\title{
Patient characteristics associated with receipt of prescription weight management medications among veterans participating in MOVE!
}

\author{
Dylan D. Thomas, MD ${ }^{1}$, Molly E. Waring, $\mathrm{PhD}^{2}$, Omid Ameli, MD MPH ${ }^{3}$, Joel I. Reisman, \\ $\mathbf{A B}^{3}$, and Varsha G. Vimalananda, $\mathbf{M D}, \mathbf{M P H}^{3,1}$ \\ ${ }^{1}$ Section of Endocrinology, Diabetes, Nutrition, and Weight Management, Department of \\ Medicine; Boston University School of Medicine. Boston, MA \\ ${ }^{2}$ Department of Allied Health Sciences, University of Connecticut. Storrs, CT \\ ${ }^{3}$ Center for Healthcare Organization and Implementation Research (CHOIR), Edith Nourse \\ Rogers Memorial Veterans Affairs Medical Center. Bedford, MA.
}

\begin{abstract}
Objective: Weight management medications (WMM) are recommended for the treatment of obesity. We examined characteristics associated with initial receipt of WMM among eligible veterans in the first year following enrollment in the Veterans Health Administration (VA) MOVE! behavioral weight management program.

Methods: Retrospective cohort study of VA patients who enrolled in MOVE! in Oct 2013-Sep 2016 with obesity or overweight with obesity-related comorbidities ( $N=153,393)$. Multivariable logistic regression models estimated predictors of having a filled prescription for WMM and for orlistat.
\end{abstract}

Results: $1.1 \%$ of these veterans received WMM. The most common WMM were orlistat (70.4\%), phentermine/topiramate (11.2\%), and bupropion/naltrexone (9.7\%). Female gender, higher BMI, obstructive sleep apnea, osteoarthritis, depression, low back pain, and alcohol abuse were associated with greater odds of use of WMM, whereas age over 65, Hispanic race/ethnicity, and required copayments were associated with lower odds. Among patients receiving WMM, older age, Black race, female gender, higher BMI, cardiovascular disease, low back pain, and congestive heart failure were associated with use of orlistat versus any other WMM.

Contact information: Varsha G. Vimalananda, MD, MPH, Center for Healthcare Organization and Implementation Research (152), Edith Nourse Rogers Memorial Veterans Affairs Medical Center, 200 Springs Rd, Bedford, MA. 01730, Telephone: (781) 687-3456, Varsha.vimalananda@va.gov.

Author contributions: Drs. Thomas and Vimalananda had full access to all of the data in the study and take responsibility for the integrity of the data and the accuracy of the data analysis

Concept and design: Thomas, Vimalananda, Waring. Acquisition, analysis, interpretation of data: Ameli, Thomas, Reisman,

Vimalananda, Waring. Drafting of manuscript: Thomas, Vimalananda. Statistical analysis: Thomas, Reisman, Vimalananda.

Supervision: Vimalananda. Critical revision of the manuscript for important intellectual content: all authors.

Disclosure: The authors declare no conflict of interest. 
Conclusion: $1.1 \%$ of patients engaged in MOVE! in the VA received WMM. WMM are underutilized among veterans. Additional research is needed to understand barriers to incorporating WMM into comprehensive obesity treatment plans.

\section{Keywords}

obesity; obesity management; veteran; antiobesity drugs; orlistat

\section{Introduction}

Among the Veterans Health Administration (VA) patient population, the prevalence of obesity was $41 \%$ and the prevalence of overweight was $37 \%$ in 2017 (1). Obesity is a chronic disease that compromises quality of life, increases healthcare costs, and is a risk factor for and increases morbidity from diabetes, depression, hypertension, coronary heart disease, stroke, osteoarthritis, obstructive sleep apnea (OSA), and several cancers (2). From 2000 to 2014, the mean body weight of veterans increased, with the most rapid rates of increase in the youngest cohorts and in women without diabetes, who gained $0.36 \mathrm{~kg} / \mathrm{year}$ during this period (3). To address the growing prevalence of overweight and obesity among veterans, every VA facility offers MOVE! ®, a comprehensive behavioral weight management program, to any veteran with overweight or obesity (4). MOVE! has evolved into the largest health-care based weight management program in the country (5). However, the efficacy of behavioral interventions is modest (6). A systematic review found that average 12-month weight loss among MOVE! participants ranged from $-0.13 \mathrm{~kg}$ to $-3.3 \mathrm{~kg}$ (7).

Weight management medications (WMM) when added to lifestyle interventions increase the likelihood of achieving $25 \%$ weight loss (8). This degree of weight loss is associated with a reduced risk of diabetes, decreased medication requirements for obesity-related comorbid conditions, and improved sexual function, urinary continence, mobility, pain, and quality of life . Bariatric surgery is also an effective treatment for weight loss, but is not appropriate for all patients or available at every VA (9). However, any veteran who is engaged in MOVE! or a similar behavioral weight management program and has a BMI $\geq 30 \mathrm{~kg} / \mathrm{m}^{2}$ or a BMI $\geq 27$ $\mathrm{kg} / \mathrm{m}^{2}$ with one or more obesity-related comorbidities is eligible to receive WMM. Therefore, WMM can fill the treatment gap between lifestyle change and surgery for many veterans who do not lose sufficient weight with MOVE! alone.

Multiple evidence-based treatment guidelines support the use of WMM including those from The Obesity Society, VA/Department of Defense, the Endocrine Society, and the American Association of Clinical Endocrinologists $(8,10,11,12)$. Participation in a behavioral weight management program is a prerequisite for WMM receipt in VA (12). MOVE! is the most commonly used program among veterans. A recent study of the efficacy of WMM in the VA found that patients who used WMM together with MOVE! achieved a significantly greater weight loss than patients who participated in MOVE! without using WMM (13), and 40\% of patients who received phentermine-topiramate achieved at least $5 \%$ weight loss in 20 weeks. Hence, there is a strong rationale to incorporate WMM more routinely into obesity treatment in VA. However, there is evidence that WMM are widely underused compared with 
pharmacotherapies for other chronic diseases (14). In the VA, a study reported that only $1 \%$ of all veterans with overweight/obesity filled a prescription for orlistat in 2010 (15). At that time, only orlistat was FDA-approved for long-term use. Since then, four new medications for long-term obesity treatment have been approved. It is not known whether use of WMM has increased in VA since 2010 in light of these newly available medications and clinical guidelines recommending their use.

Clinically relevant patient characteristics such as BMI, gender, comorbidities, and age are considered when deciding whether to use WMM and which WMM to prescribe $(8,10,11$, 12). In the 2010 study of veterans, higher BMI, female gender, younger age, and certain comorbid and psychiatric conditions were associated with greater odds of orlistat use (15). The relationships of these characteristics with more contemporary use of WMM in the VA has not been described. In this study, we examined the proportion of veterans participating in MOVE! who received an initial prescription for WMM and examined demographic and clinical factors associated with its receipt. We also examined factors associated with receipt of orlistat versus other WMM.

\section{Methods}

\section{Study design and sample}

We conducted a retrospective cohort study of VA patients who enrolled in MOVE! from October 2013 to September 2016. Data from the electronic health record were accessed through the VA Corporate Data Warehouse, which is a data repository for VA facilities across the nation. This study was approved by Bedford VA Institutional Review Board.

Patients were included in the cohort if they initiated MOVE! in October 2013 to September 2016 and had either a BMI $\geq 30 \mathrm{~kg} / \mathrm{m}^{2}$ or a BMI $\geq 27 \mathrm{~kg} / \mathrm{m}^{2}$ with obesity-related comorbidities (diabetes, hypertension, hyperlipidemia, cardiovascular disease, OSA, nonalcoholic fatty liver disease, osteoarthritis, or depression) at the time of MOVE! initiation. Patients were excluded if they received WMM in the year prior to MOVE! initiation, which may have occurred in cases where patients previously participated in nonVA behavioral weight management program. MOVE! initiation was defined as having at least one MOVE! visit in the study period, without a MOVE! visit in the previous six months. We excluded patients without a recorded weight within 30 days before or 7 days after they enrolled in MOVE!, those without height within 5 years of enrolling in MOVE!, and those $<18$ years of age.

The methods used to identify participants in MOVE! were those described by the national MOVE! program in prior literature (16). In brief, we identified patients with administrative visits carrying the 372 or 373 stop codes associated with MOVE! programs while excluding codes that are associated with employee MOVE!, research studies, or TeleMOVE!, which is an obesity management program delivered remotely to veterans.

\section{Outcomes}

The primary outcome was at least one initial filled prescription (receipt) of any weight management medication approved for long-term use (i.e. orlistat, liraglutide $3 \mathrm{mg}$, lorcaserin, 
phentermine/topiramate, or bupropion/naltrexone) or short-term use (phentermine) within 1 year of the MOVE! initiation date. We excluded patients who received these medications tagged as investigational or used in a trial. When phentermine and topiramate were prescribed separately as generics but within 30 days of one another, this was considered as phentermine/topiramate. The same was done for bupropion and naltrexone.

\section{Explanatory variables}

We considered the following variables to be possible predictors of receipt of WMM: age, gender, BMI category (overweight, obesity class I (BMI 30-34.9), obesity class II (BMI 35 - 39.9), obesity class III (BMI 240$)$ ), required copayment, race/ethnicity, obesity-related comorbidities (diabetes, hypertension, hyperlipidemia, OSA, osteoarthritis, depression, low back pain), alcohol abuse, and substance abuse. Additional comorbidities examined include peripheral vascular disease, cerebrovascular disease, dementia, chronic obstructive pulmonary disease, liver disease, renal disease, psychosis, bipolar disorder or mania (17).

\section{Statistical analysis}

We estimated unadjusted associations between each predictor and receipt of WMM using chi-squared tests. We used logistic regression models to estimate the association between patient characteristics and receipt of WMM. We constructed an adjusted model by individually adding factors that were associated with receipt of WMM outcome at the $\mathrm{p}<$ 0.10 level sequentially, in order of largest to smallest crude odds ratio. Variables were retained in the model if the $95 \%$ confidence interval (CI) of the adjusted OR (aOR) for any level of the variable was statistically significant. We used this same approach to construct an adjusted model of the receipt of orlistat compared with receipt of any other WMM, among the subsample receiving any of the WMM. Analyses were conducted using SAS 9.4 (SAS Institute, Inc., Cary, NC).

\section{Results}

Of patients who had one or more MOVE! visits in October 2013 to September 2016 $(\mathrm{N}=298,704)$, we excluded patients with a MOVE! visit in the preceding 6 months $(\mathrm{N}=38,195)$ to identify MOVE! initiators during this period $(\mathrm{N}=260,509)$. We excluded patients who did not have a qualifying height $(\mathrm{N}=1,801)$ or weight $(\mathrm{N}=31,341)$, were under age $18(\mathrm{~N}=5)$, or had $\mathrm{BMI}<27(\mathrm{~N}=16,503)$, $\mathrm{BMI}<30$ without a comorbid condition $(\mathrm{N}=2,934)$, or ineligible stop codes $(54,33)$. We excluded subjects who received WMM in the year before their MOVE! initiation date $(\mathrm{N}=1,499)$. This resulted in a sample of 153,393 veterans: (Table 1) $34.0 \% \geq 65$ years old, $84.9 \%$ male, $13.0 \%$ overweight with an obesity-related comorbidity, $36.3 \%$ with class I obesity, $27.8 \%$ with class II obesity, and $22.9 \%$ with class III obesity. The most common comorbidities were hypertension (64.0\%), hyperlipidemia $(58.1 \%)$, and diabetes $(37.0 \%)$.

Only $1.1 \%(\mathrm{n}=1,719)$ received an initial prescription WMM in the year following MOVE! initiation. The most common prescription was for orlistat (70.4\%), followed by phentermine/ topiramate (combined generic and brand name 11.2\%) and bupropion/naltrexone (combined generic and brand name: 9.7\%; Table 2).

Obesity (Silver Spring). Author manuscript; available in PMC 2020 July 01. 


\section{Predictors of use of WMM}

Receipt of WMM was more likely among the following groups of veterans: 45-54 years compared to $18-34$ years $(\mathrm{aOR}=1.2,95 \% \mathrm{CI}$ : $1.0-1.5)$, female gender $(\mathrm{aOR}=2.1,95 \% \mathrm{CI}$ : $1.8-2.3)$, and class I obesity (aOR=1.9, 95\%CI: $1.4-2.4)$, class II obesity $(\mathrm{aOR}=3.2,95 \%$ CI: $2.5-4.1$ ), class III obesity (aOR=5.2, 95\%CI: $4.1-6.7$ ) compared to overweight (Table 3). All of the obesity-related comorbidities that were included in the multivariate model were associated with greater likelihood of receipt of WMM (osteoarthritis aOR=1.3, 95\% CI: $1.2-1.4$, OSA aOR=1.3, 95\% CI: $1.2-1.5$, depression aOR=1.1, 95\% CI: $1.0-1.2$, low back pain aOR=1.2, 95\% CI: $1.1-1.3$ ). Receipt of WMM was also more likely among veterans with a history of alcohol abuse (aOR=2.0, 95\% CI: $1.5-2.7)$. Patients aged over 65 years ( $\mathrm{aOR}=0.7,95 \%$ CI: $0.5-0.8$ ), those of Hispanic ethnicity ( $\mathrm{aOR}=0.8,95 \%$ CI: $0.6-0.9$, compared to non-Hispanic white), and those who had required copayments $(\mathrm{aOR}=0.8,95 \%$ CI: $0.7-0.8$ ) were less likely to receive WMM (Table 3).

\section{Predictors of orlistat use compared with any other use of WMM}

Characteristics associated with higher odds of receiving orlistat compared with other WMM were: age $\geq 65$ years compared to $18-34$ years ( $\mathrm{aOR}=2.4$, $95 \%$ CI: $1.5-3.9$ ), Black/nonHispanic race/ethnicity (aOR=1.5, 95\% CI: $1.2-2.0$, compared to non-Hispanic white), female gender (aOR=1.5, 95\% CI: $1.1-2.0)$, and any obesity class (class I obesity aOR=2.1, 95\% CI: $1.2-3.7$, class II obesity aOR=2.1, 95\% CI: $1.2-3.7$, class III obesity aOR=1.8, 95\% CI: $1.1-3.2$ ) compared to overweight (Table 4). Patients with cardiovascular disease ( $\mathrm{aOR}=2.8,95 \%$ CI: $1.2-6.4)$, low back pain (aOR=1.4, 95\% CI: $1.1-1.8)$, and congestive heart failure ( $\mathrm{aOR}=1.9,95 \% \mathrm{CI}: 1.1-3.4)$ were also more likely to receive orlistat compared to other WMM. Patients with required copayments (aOR=0.7, 95\% CI: 0.6 -0.9 ), had a history of alcohol abuse (aOR=0.4, 95\% CI: $0.2-0.9)$, or had a history of substance abuse $(\mathrm{aOR}=0.4,95 \% \mathrm{CI}: 0.3-0.5)$ were less likely to receive orlistat compared to other WMM.

\section{Discussion}

We found that use of WMM in VA remains extremely low, despite the availability of four new WMM since 2010 and several clinical guidelines recommending their use as part of a comprehensive treatment plan for obesity. From October 2013 to September 2016, orlistat was by far the most commonly prescribed obesity medication, comprising $70.4 \%$ of prescriptions, with very low use of newer long-term medications and the older short-term medication, phentermine. The strongest predictors of receipt of any WMM were female gender, higher BMI and alcohol abuse. Particularly strong predictors of orlistat receipt versus any other WMM were age $\geq 65$, higher BMI, cardiovascular disease, and congestive heart failure.

The low rate of use of WMM in VA that we report here is consistent with the findings from the 2010 VA study, which found that only $2.3 \%$ of eligible patients received orlistat and that veterans with higher BMI were more likely to be prescribed WMM (15). This low rate of use is also similar to that reported in non-VA settings where less than $2 \%$ of potentially eligible patients in the general population were treated with $\operatorname{WMM}(14,18)$. The comparably 
low rates of use of WMM in and outside the VA are surprising. Insurance coverage is a major barrier to use of WMM outside VA (14), but is a much lesser issue in VA, where veterans can receive prescribed WMM at no or relatively low out-of-pocket cost. This suggests that clinician or patient barriers beyond insurance drive underuse of WMM in VA; these same factors may contribute to underuse of WMM outside VA.

The pattern of WMM use we observed differs from that in the general U.S. population, among which phentermine is by far the most common prescription among WMM. Within VA, clinician choice between WMM may be driven more by clinical appropriateness and physician familiarity than by cost. In addition, pharmacy oversight limits phentermine treatment to 3 months, whereas outside of VA, phentermine can be prescribed off-label for longer periods. In addition, outside VA, clinicians face a lack of insurance coverage for WMM and may therefore prescribe the medication that presents the lowest out-of-pocket cost to patients, which is phentermine. $(19,20)$.

Our finding of a higher rate of use of WMM among women and lower use among those $\geq 65$ years is consistent with the 2010 VA study (15). It is not clear whether women are more likely to be offered WMM or more likely to ask for or accept them, and older patients less likely. Lower use among older patients may also be explained by a combination of clinicianand patient-level factors including a risk/benefit calculation that suggests higher risk, or appropriate prioritization of other medical conditions. We found that required copayments were associated with lower odds of receipt of WMM. Financial barriers are commonly cited by persons with obesity as a reason for not seeking professional assistance with weight loss (37). In the VA, patients are assigned a priority group based on financial need and the degree of service-connected disability among other special eligibilities. Those in priority group 1 do not have a medication copay. Those in groups $2-8$ do have a medication copay; Tier 3 brand name medications are $\$ 11 /$ month with an annual $\$ 700$ cap. These costs are significantly less than the out-of-pocket costs for WMM, which are usually well over \$100 month, but elimination or further reduction of copays may reduce a barrier to use of WMM.

Treatment for obesity in general tends to be suboptimal, as per ambulatory care performance on quality indicators for patients with obesity outside VA (21). The barriers to obesity treatment reported by patients include a perceived lack of support from clinicians (22), and the barriers reported by primary care providers (PCPs) include a perceived lack of effective treatments for obesity, inadequate reimbursement for time spent on weight management, and frustration with patients' inability to lose weight $(23,24)$. On top of these challenges, PCPs report barriers to use of WMM specifically; these include limited experience and concern about adverse reactions with WMM (25). Following the withdrawal of several older obesity medications including aminorex, fenfluramine, dexfenfluramine, phenylpropanolamine, rimonabant, and sibutramine from the market, clinicians and patients may have residual concerns about the long-term safety of obesity medications (26). These concerns may contribute to why PCPs only rarely recommend WMM for patients with obesity in their practice (27). However, orlistat is approved for use at a lower strength without a prescription, and has a long history of use and a good safety profile. The newer WMM including lorcaserin, liraglutide, and phentermine/topiramate have demonstrated a positive risk/benefit ratio in phase III and IV clinical trials $(28,29,30,31,32)$. Additional long term 
cardiovascular safety trials are underway. These data may lead to increased use of WMM in the future. In an online survey, people with obesity identified that the percent weight loss was the most important factor to them in choosing among WMM and that they would be willing to pay $\$ 10$ per month per percentage point weight loss that a pharmacotherapy could provide (33). Further exploration of clinician and patient attitudes is needed to identify ways to realign expectations, design interventions to address barriers, support patients with obesity, and offer WMM to appropriate patients.

Our finding that receipt of WMM was more likely among patients with higher BMI, OSA, osteoarthritis, depression, and low back pain suggest that patients with more severe obesity and obesity-related comorbidities are more likely to receive WMM. Veterans with higher BMI have been previously shown to be more likely to receive clinical preventive services in the VA (34). We also found a strong positive association between history of alcohol abuse and receipt of WMM. This may be due to greater contact of these veterans with the healthcare system and subsequently greater opportunities to discuss and address weight management; this warrants further study. It may also be due to the other indications of bupropion for depression and smoking cessation and naltrexone for alcohol and opioid dependence. Hence, a portion of the generic naltrexone/bupropion which we assumed was being prescribed for obesity may actually be for two different FDA approved indications and not intended as obesity treatment. However, this would lead to overestimation of the overall use of WMM and hence our conclusion that WMM remain underused remains valid. Alternatively, providers may be using bupropion/naltrexone as a treatment for both obesity and other comorbid conditions such as alcohol or substance abuse which are more prevalent in veterans than in the general population $(35,36)$.

Several patient characteristics were associated with the choice of orlistat versus other WMM, among patients who received WMM. Orlistat was favored over other WMM in veterans who were older, Black/non-Hispanic, and with higher BMI. Orlistat use was also more likely in female veterans, and veterans with cardiovascular disease, low back pain, or congestive heart failure. Conversely, patients with required copayments, alcohol abuse, or substance abuse were less likely to receive orlistat versus another of the WMM. It is possible that some patient comorbidities are driving choice among WMM. For example, clinicians may favor orlistat among older patients or those with cardiovascular disease or congestive heart failure due to confidence in its cardiovascular safety. Those with diabetes may preferentially receive liraglutide (which also helps with glycemic control) (32). Obesity guidelines recommend that patients with alcohol and substance abuse histories preferentially receive orlistat or liraglutide (10); therefore our finding of lower use of orlistat relative to all other WMM among such patients warrants closer analysis. Physician familiarity with orlistat may also explain why it is the most commonly prescribed medication, while its gastrointestinal side effects may limit its acceptability to patients and contribute to its overall underuse. Given the small sample size for medications other than orlistat, we had limited power to further assess the factors associated with the choice between WMM other than orlistat and further investigation is warranted. 


\section{Limitations}

The study did not examine whether patients had a prior intolerance or failure to respond to WMM or a relative or absolute contraindication to their use, and did not examine the effects of the number of MOVE! visits or the duration of MOVE! participation on use of WMM. For example, it may be that providers are more likely to recommend WMM with longer duration of MOVE! participation. Our primary outcome was an initial prescription of WMM within the first year after MOVE! initiation. During this period, patients may be experiencing some weight loss from lifestyle changes which may justify postponing WMM initiation, so future studies should examine whether WMM use increases over a longer time period after MOVE! initiation. It may be that other patient characteristics not available in this study drive prescribing patterns. For example, we did not have information on how clinicians and/or patients decided whether the patient should receive WMM, or patients' weight loss histories including prior participation in behavioral weight loss treatment and/or prior use of WMM. We did not examine duration of use of WMM, which would provide additional information on the extent to which patients are using and potentially benefiting from WMM. A not insignificant number of patients $(\mathrm{N}=36,142,12.4 \%)$ were excluded if they did not have a documented weight or height around the time of MOVE! initiation. This could indicate that they are not genuine MOVE! participants, as these recorded measurements are required at each MOVE! visit, or it could indicate inconsistent application of the MOVE! protocol.

The VA Pharmacy Benefits Management (PBM) provides Criteria For Use (CFU) to aid clinicians select and monitor appropriate patients. During the study period, the CFU required at least 3 months of participation in MOVE! prior to initiation of WMM. Insofar as patients with fewer than 3 months of participation were included in our cohort, the proportion of eligible patients who receive WMM may be slightly higher than 1.2\%. Subsequently, a VA Health Services Research and Development Service State of the Art conference on weight management in veterans concluded that WMM are underused and called for system-level changes to improve population-based weight management $(4,38,39)$. This was followed by a new PBM CFU for WMM in July 2016 that eliminated the requirements for 3 months of MOVE! participation prior to initiation of WMM. With this change, a significant barrier to the availability of WMM has been eliminated. The effects of these interventions were not assessed by this study which only included visits until September 2016. Studies of use of WMM following these policy changes are needed to understand their impact.

\section{Implications}

Our findings have implications for system improvement efforts given that nearly 4 million veterans with overweight or obesity receive care in the VA, and the burden of obesity-related co-morbidities is likely to increase over time (1). Low use of WMM among eligible patients suggests that many patients are not receiving guideline-concordant obesity treatment. Data are needed on factors at every level - system, clinician, patient - that influence use of WMM to supplement behavioral weight loss treatment. Experience with uptake of other medications indicates that the reasons for adoption often do not involve national CFU or even site-level written policies but may be influenced by informal local policies and opinion climates $(40,41,42,43,44,45)$. These, in turn, may reflect clinicians' relative valuations of 
safety of WMM, efficacy, and workflow impact. More data on outcomes of WMM among veterans and development of workflows that support initiation of WMM and monitoring may promote use at the local level. Finally, our results suggest that there are significant barriers to use of WMM even when insurance is not a limitation, which has relevance to the treatment of obesity outside the VA.

\section{Conclusions}

In summary, we found that only $1 \%$ of VA patients who initiated MOVE! were started on an obesity pharmacotherapy within the first year. Females and those with higher BMI and obesity-related comorbidities were more likely to receive WMM. Underuse occurred despite detailed treatment guidelines, lack of insurance barriers to availability of WMM, and millions of veterans who need additional support for weight loss. Additional studies and interventions are needed to support use of WMM and to optimize the treatment of veterans with obesity.

\section{Acknowledgements}

The authors would like to acknowledge Stephanie H. Chan, MPH for her assistance in defining the cohort.

Funding information: This work was supported in part by the National Institutes of Health [UL1TR001430, P30DK046200, T32DK007201].

\section{References}

1. Breland JY, Phibbs CS, Hoggatt KJ, Washington DL, Lee J, Haskell S, et al. The obesity epidemic in the Veterans Health Administration: prevalence among key populations of women and men veterans. J Gen Intern Med 2017;32: 11-17.

2. Finkelstein EA, Trogdon JG, Cohen JW, Dietz W. Annual medical spending attributable to obesity: payer-and service-specific estimates. Health Aff (Millwood) 2009;28: 822-831.

3. Tamas MJ, Khakharia A, Rothenberg RB, Phillips LS. Weight Trends in Veterans With and Without Diabetes, 2000 to 2014. Obesity 2018;26: 1949-1957. [PubMed: 30417970]

4. Raffa SD, Maciejewski ML, Zimmerman LE, Damschroder LJ, Estabrooks PA, Ackermann RT, et al. A system-level approach to overweight and obesity in the Veterans Health Administration. Journal of General Internal Medicine 2017;32: 79-82. [PubMed: 28271428]

5. Damschroder LJ, Goodrich DE, Robinson CH, Fletcher CE, Lowery JC. A systematic exploration of differences in contextual factors related to implementing the MOVE! weight management program in VA: a mixed methods study. BMC Health Services Research 2011;11: 248. [PubMed: 21961925]

6. Vimalananda V, Damschroder L, Janney CA, Goodrich D, Kim HM, Holleman R, et al. Weight loss among women and men in the ASPIRE-VA behavioral weight loss intervention trial. Obesity 2016;24: 1884-1891. [PubMed: 27488278]

7. Maciejewski ML, Shepherd-Banigan M, Raffa SD, Weidenbacher HJ. Systematic review of behavioral weight management program MOVE! for veterans. American Journal of Preventive Medicine 2018;54: 704-714. [PubMed: 29550164]

8. Apovian CM, Aronne LJ, Bessesen DH, McDonnell ME, Murad MH, Pagotto U, et al. Pharmacological management of obesity: an endocrine society clinical practice guideline. The Journal of Clinical Endocrinology \& Metabolism 2015;100: 342-362. [PubMed: 25590212]

9. Maciejewski ML, Arterburn DE, Berkowitz TS, Weidenbacher HJ, Liu CF, Olsen MK, et al. Geographic Variation in Obesity, Behavioral Treatment, and Bariatric Surgery for Veterans. Obesity 2019;27: 161-165. [PubMed: 30421849]

10. Garvey WT, Mechanick JI, Brett EM, Garber AJ, Hurley DL, Jastreboff AM, et al. American Association of Clinical Endocrinologists and American College of Endocrinology Comprehensive 
clinical practice puidelines for medical care of patients with obesity. Endocrine Practice 2016;22 Suppl 3: 1-203.

11. Jensen MD, Ryan DH, Apovian CM, Ard JD, Comuzzie AG, Donato KA, et al. 2013 AHA/ACC/TOS Guideline for the Management of Overweight and Obesity in Adults. Circulation 2014;129: S102-S138. [PubMed: 24222017]

12. Department of Veterans Affairs. VA/DoD clinical practice guideline for screening and management of overweight and obesity 2014.

13. Grabarczyk TR. Observational comparative effectiveness of pharmaceutical treatments for obesity within the Veterans Health Administration. Pharmacotherapy: The Journal of Human Pharmacology and Drug Therapy 2018;38: 19-28.

14. Thomas CE, Mauer EA, Shukla AP, Rathi S, Aronne LJ. Low adoption of weight loss medications: A comparison of prescribing patterns of antiobesity pharmacotherapies and SGLT 2s. Obesity 2016;24: 1955-1961. [PubMed: 27569120]

15. Del Re A, Frayne SM, Harris AH. Antiobesity medication use across the veterans health administration: Patient-level predictors of receipt. Obesity 2014;22: 1968-1972. [PubMed: 24931332]

16. Chan SH, Raffa SD. Examining the dose-response relationship in the Veterans Health Administration's MOVE! ® weight management program: a nationwide observational study. Journal of General Internal Medicine 2017;32: 18-23. [PubMed: 28271425]

17. Elixhauser A, Steiner C, Harris DR, Coffey RM. Comorbidity measures for use with administrative data. Medical care 1998: 8-27. [PubMed: 9431328]

18. Samaranayake NR, Ong KL, Leung RY, Cheung BM. Management of obesity in the National Health and Nutrition Examination Survey (NHANES), 2007-2008. Annals of epidemiology 2012;22: 349-353. [PubMed: 22305325]

19. Hampp C, Kang EM, Borders-Hemphill V. Use of prescription antiobesity drugs in the United States. Pharmacotherapy: The Journal of Human Pharmacology and Drug Therapy 2013;33: 1299_ 1307.

20. Block JP, Choudhry NK, Carpenter DP, Fischer MA, Brennan TA, Tong AY, et al. Time series analyses of the effect of FDA communications on use of prescription weight loss medications. Obesity 2014;22: 943-949. [PubMed: 23929685]

21. Ma J, Xiao L, Stafford RS. Adult obesity and office-based quality of care in the United States. Obesity 2009;17: 1077-1085. [PubMed: 19197264]

22. Nemeth LS, Rice LJ, Potts M, Melvin C, Jefferson M, Hughes-Halbert C. Priorities and preferences for weight management and cardiovascular risk reduction in primary care. Family \& community health 2017;40: 245-252. [PubMed: 28525445]

23. Foster GD, Wadden TA, Makris AP, Davidson D, Sanderson RS, Allison DB, et al. Primary care physicians' attitudes about obesity and its treatment. Obesity research 2003;11: 1168-1177. [PubMed: 14569041]

24. Leverence RR, Williams RL, Sussman A, Crabtree BF, Clinicians RN. Obesity counseling and guidelines in primary care: a qualitative study. American journal of preventive medicine 2007;32: 334-339. e331. [PubMed: 17383565]

25. Simon R, Lahiri SW. Provider practice habits and barriers to care in obesity management in a large multicenter health system. Endocrine Practice 2018;24: 321-328. [PubMed: 29561192]

26. Ingelfinger JR, Rosen CJ. Lorcaserin-Elixir or Liability? New England Journal of Medicine 2018;379: 1174-1175. [PubMed: 30145932]

27. Phelan S, Nallari M, Darroch FE, Wing RR. What do physicians recommend to their overweight and obese patients? The Journal of the American Board of Family Medicine 2009;22: 115-122. [PubMed: 19264934]

28. Colman E, Golden J, Roberts M, Egan A, Weaver J, Rosebraugh C. The FDA's assessment of two drugs for chronic weight management. New England Journal of Medicine 2012;367: 1577-1579. [PubMed: 23050510]

29. Bohula EA, Wiviott SD, McGuire DK, Inzucchi SE, Kuder J, Im K, et al. Cardiovascular safety of lorcaserin in overweight or obese patients. New England Journal of Medicine 2018;379: 1107 1117. [PubMed: 30145941] 
30. Gadde KM, Allison DB, Ryan DH, Peterson CA, Troupin B, Schwiers ML, et al. Effects of lowdose, controlled-release, phentermine plus topiramate combination on weight and associated comorbidities in overweight and obese adults (CONQUER): a randomised, placebo-controlled, phase 3 trial. The Lancet 2011;377: 1341-1352.

31. Marso SP, Daniels GH, Brown-Frandsen K, Kristensen P, Mann JF, Nauck MA, et al. Liraglutide and cardiovascular outcomes in type 2 diabetes. New England Journal of Medicine 2016;375: $311-$ 322. [PubMed: 27295427]

32. Pi-Sunyer X, Astrup A, Fujioka K, Greenway F, Halpern A, Krempf M, et al. A randomized, controlled trial of $3.0 \mathrm{mg}$ of liraglutide in weight management. New England Journal of Medicine 2015;373: 11-22. [PubMed: 26132939]

33. Doyle S, Lloyd A, Birt J, Curtis B, Ali S, Godbey K, et al. Willingness to pay for obesity pharmacotherapy. Obesity 2012;20: 2019-2026. [PubMed: 22301901]

34. Yancy WS Jr, McDuffie JR, Stechuchak KM, Olsen MK, Oddone EZ, Kinsinger LS, et al. Obesity and receipt of clinical preventive services in veterans. Obesity 2010;18: 1827-1835. [PubMed: 20203629]

35. Teeters JB, Lancaster CL, Brown DG, Back SE. Substance use disorders in military veterans: prevalence and treatment challenges. Substance abuse and rehabilitation 2017;8: 69. [PubMed: 28919834]

36. Bohnert AS, Ilgen MA, Bossarte RM, Britton PC, Chermack ST, Blow FC. Veteran status and alcohol use in men in the United States. Military medicine 2012;177: 198-203. [PubMed: 22360067]

37. Kaplan LM, Golden A, Jinnett K, Kolotkin RL, Kyle TK, Look M, et al. Perceptions of barriers to effective obesity care: results from the national ACTION study. Obesity 2018;26: 61-69. [PubMed: 29086529]

38. Atkins D. Improving Weight Management among Veterans. Journal of General Internal Medicine 2017: 1-3.

39. Semla TP, Ruser C, Good CB, Yanovski SZ, Ames D, Copeland LA, et al. Pharmacotherapy for Weight Management in the VHA. J Gen Intern Med 2010: 70-73. [PubMed: 20697963]

40. McCullough MB, Chou AF, Solomon JL, Petrakis BA, Kim B, Park AM, et al. The interplay of contextual elements in implementation: an ethnographic case study. BMC Health Services Research 2015;15: 62. [PubMed: 25890333]

41. Kramer JR, Kanwal F, Richardson P, Giordano TP, Petersen LA, El-Serag HB. Importance of patient, provider, and facility predictors of hepatitis $\mathrm{C}$ virus treatment in veterans: a national study. Am J Gastroenterol 2011;106: 483-491. [PubMed: 21063393]

42. Huskamp HA, O’Malley AJ, Horvitz-Lennon M, Taub AL, Berndt ER, Donohue JM. How quickly do physicians adopt new drugs? The case of second-generation antipsychotics. Psychiatr Serv 2013;64: 324-330. [PubMed: 23280376]

43. Knudsen HK, Ducharme LJ, Roman PM. Early adoption of buprenorphine in substance abuse treatment centers: Data from the private and public sectors. Journal of Substance Abuse Treatment 2006;30: 363-373. [PubMed: 16716852]

44. Agha L, Molitor D. The local influence of pioneer investigators on technology adoption: evidence from new cancer drugs. The Review of Economics and Statistics 2018;100: 29-44. [PubMed: 29755142]

45. Lublóy Á. Factors affecting the uptake of new medicines: a systematic literature review. BMC Health Services Research 2014;14: 469. [PubMed: 25331607] 


\section{What is already known about this subject?}

- Obesity is a significant health problem among veterans.

- Weight management medications are underused in eligible patients.

\section{What does your study add?}

- $\quad$ Only $1.1 \%$ of patients who initiated MOVE! from Oct. 2013 - Sep. 2016 received prescription for these medications.

- $\quad$ Higher BMI, female gender, and the presence of co-morbid conditions were associated with higher odds of medication receipt; age over 65 years and needing a copayment for medication were associated with lower odds of medication receipt. 


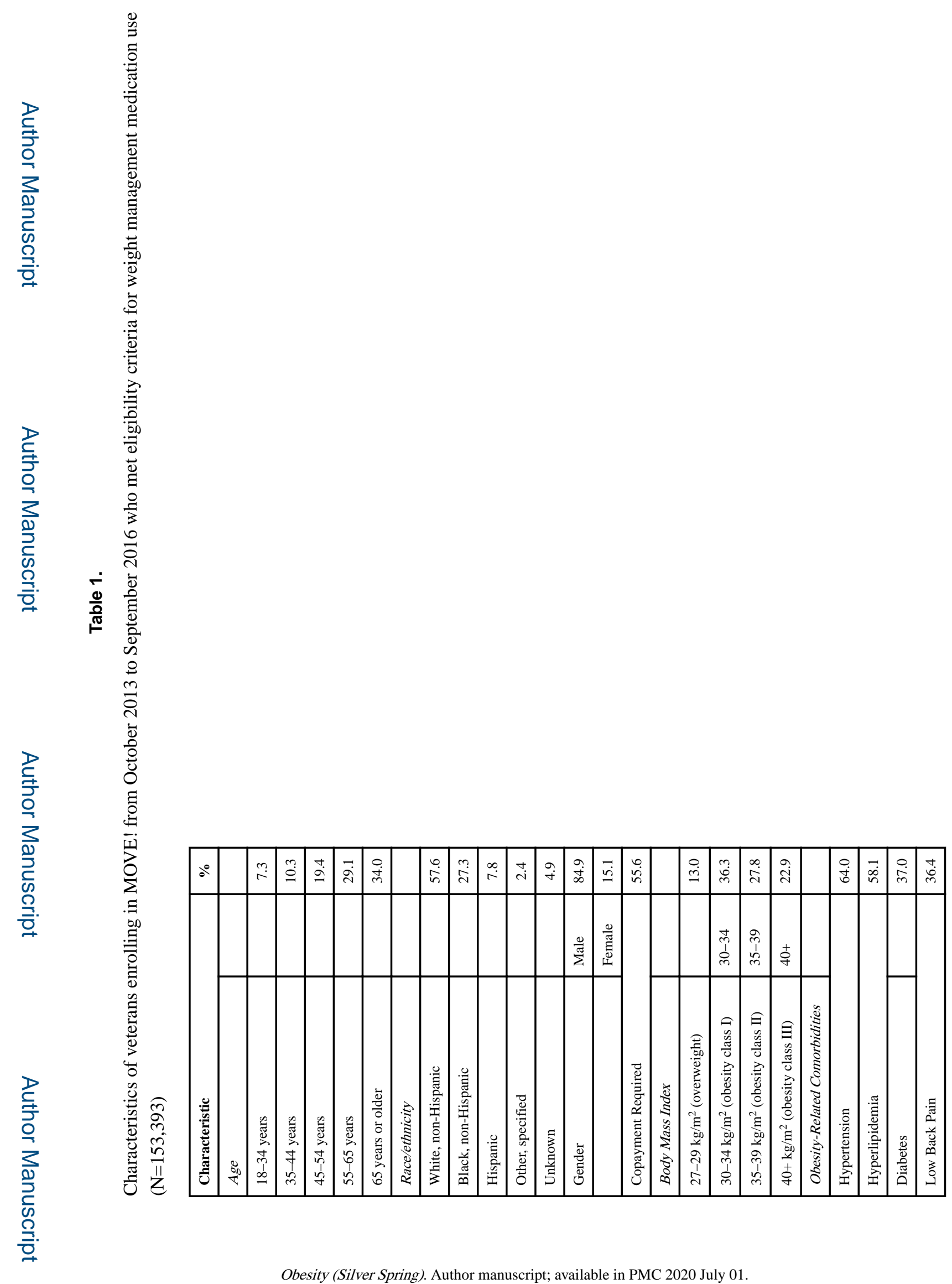




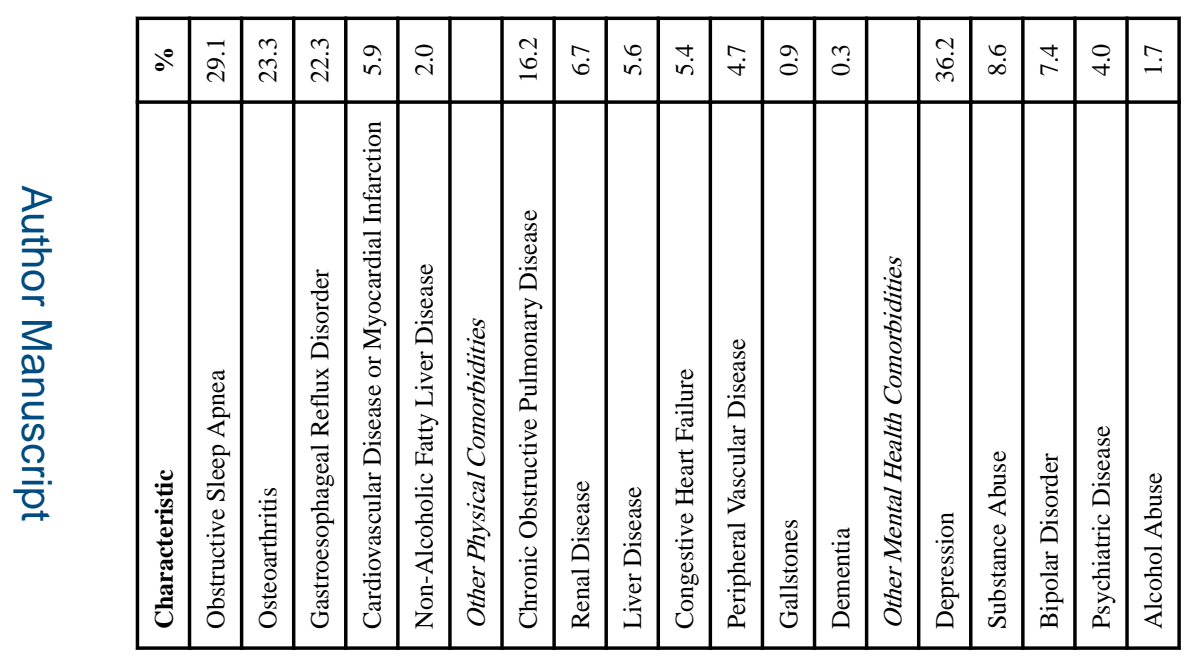

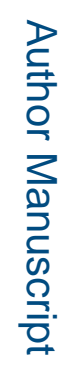

롤

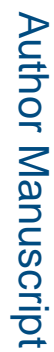




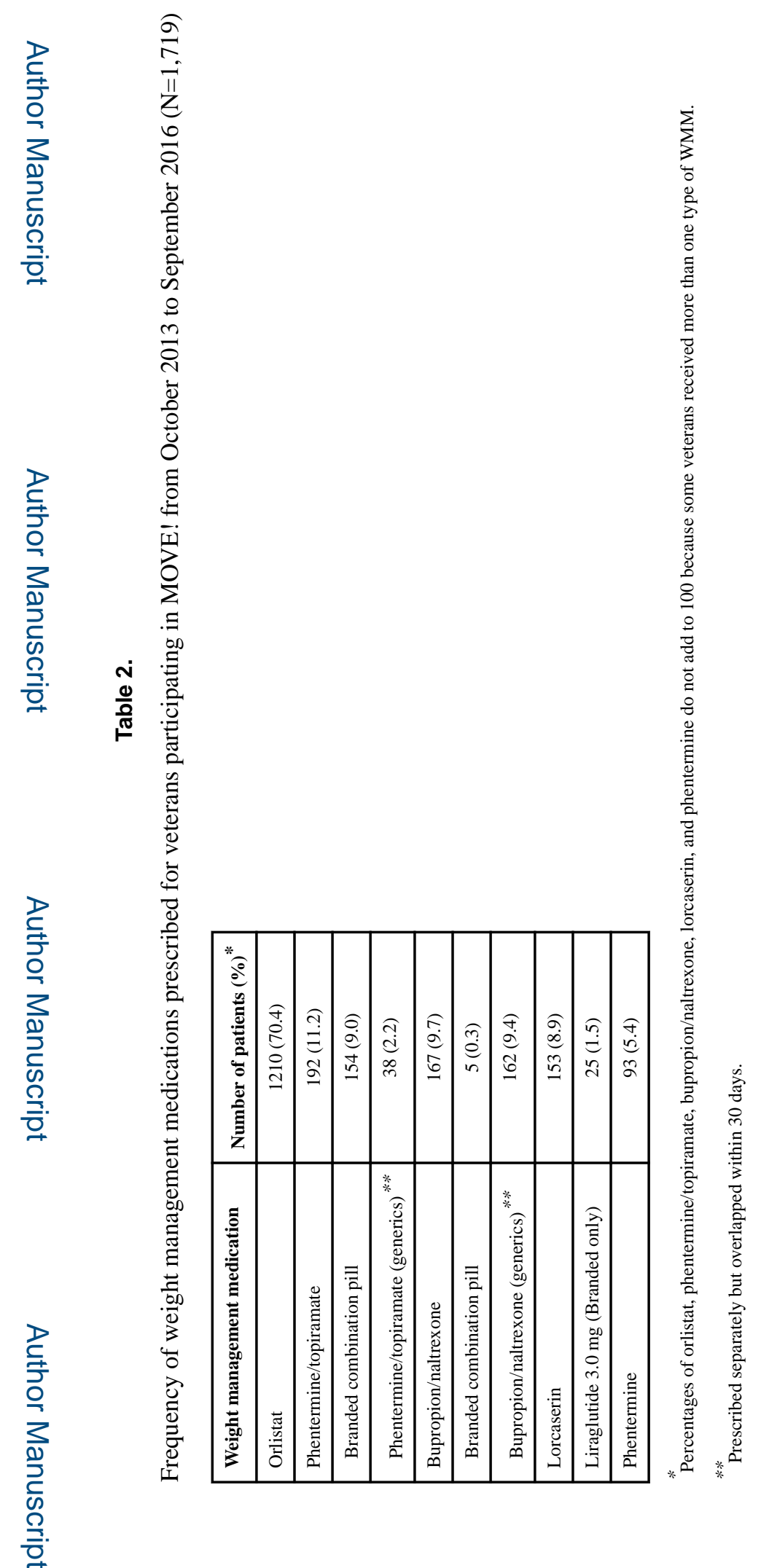

Obesity (Silver Spring). Author manuscript; available in PMC 2020 July 01. 


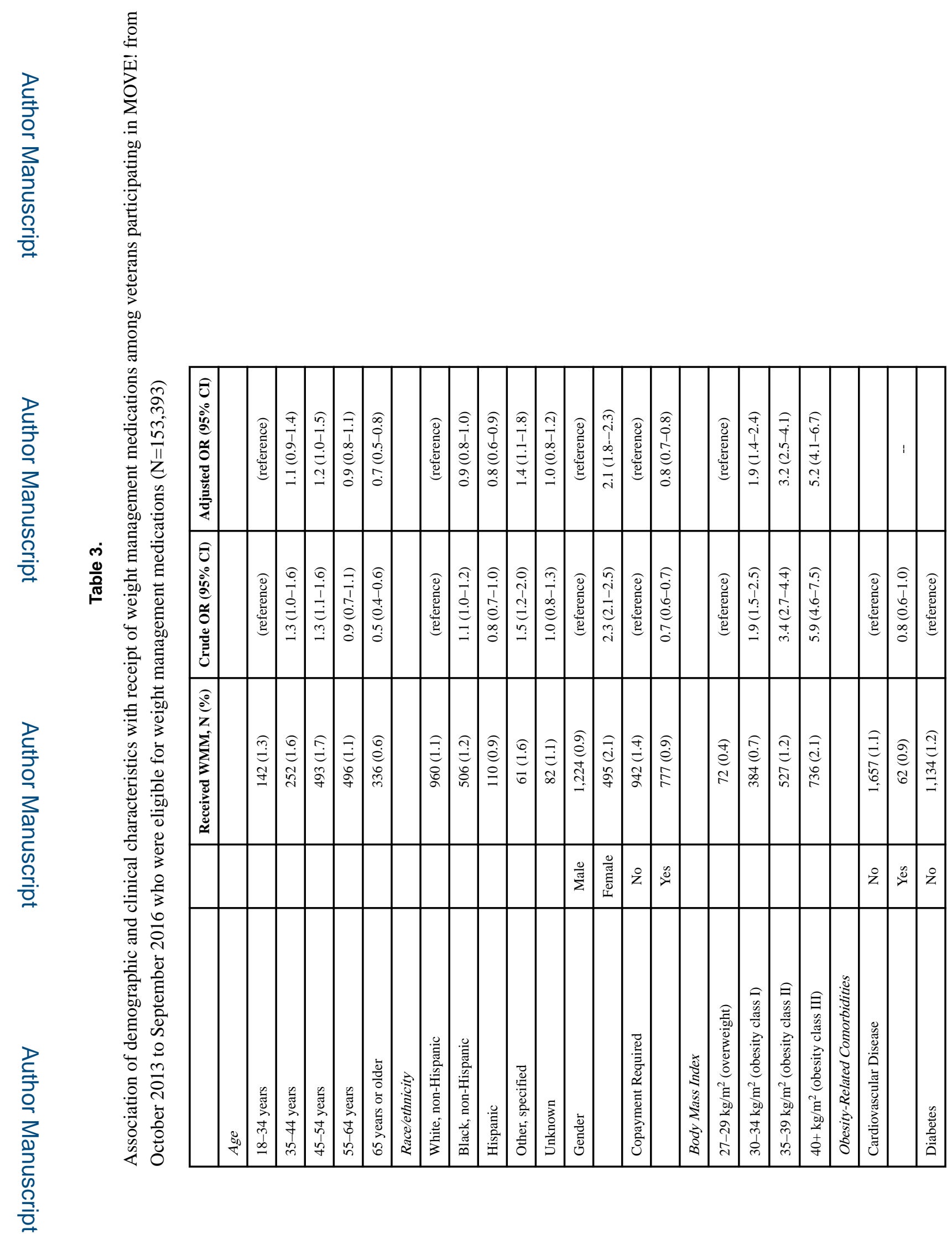

Obesity (Silver Spring). Author manuscript; available in PMC 2020 July 01. 


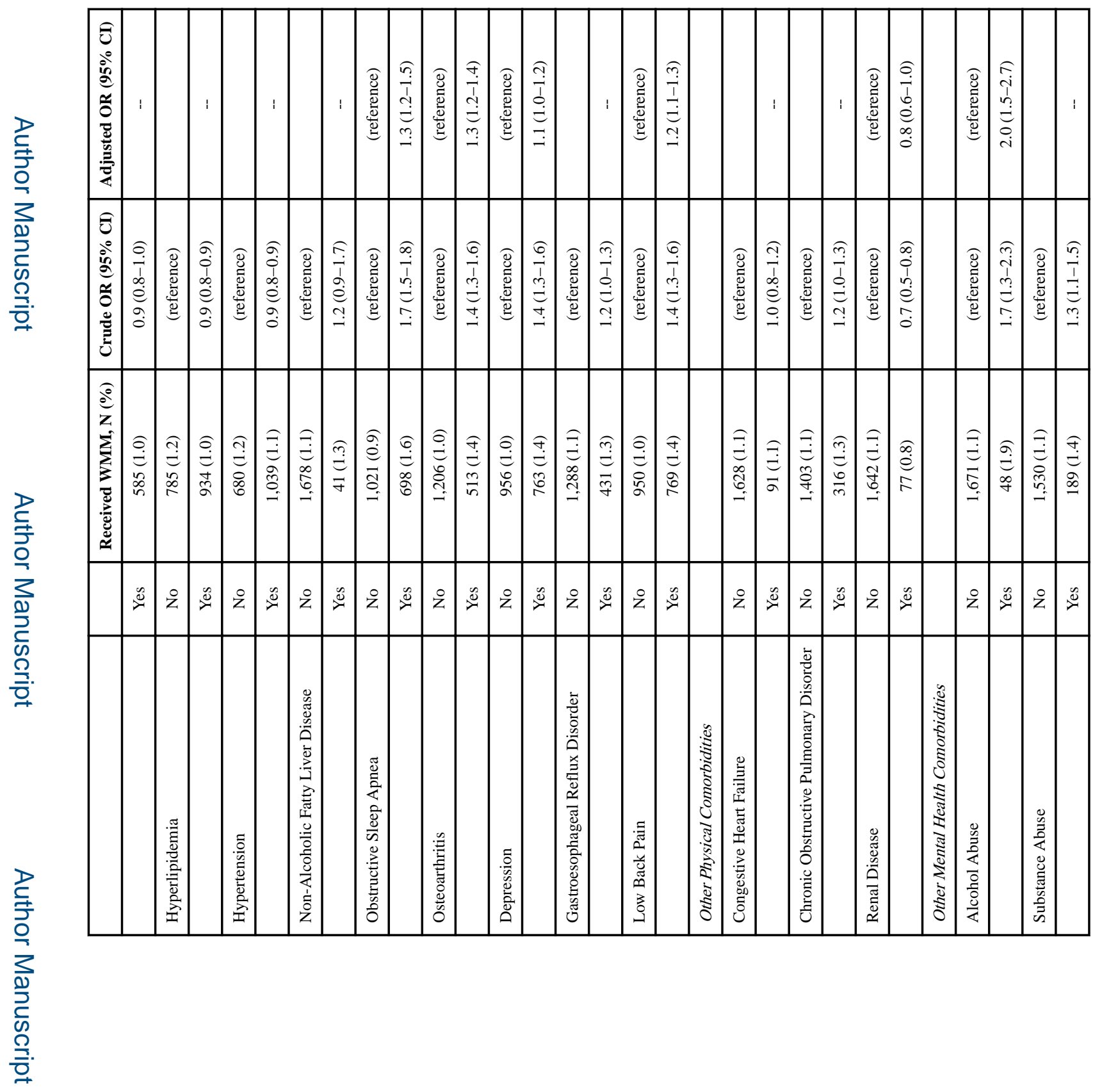

로을 

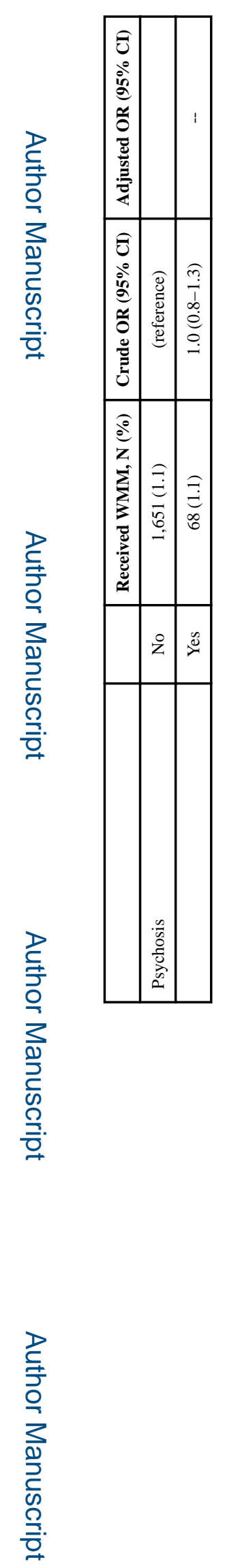
Table 4.

Association of demographic and clinical characteristics with receipt of orlistat compared to other weight management medications among veterans participating in MOVE! from October 2013 to September 2016 who received weight management medications $(\mathrm{N}=1,719)$

\begin{tabular}{|c|c|c|c|c|}
\hline & & $\begin{array}{c}\text { Received Orlistat, } \mathrm{N} \text { (\% of } \\
\text { WMM) }\end{array}$ & Crude OR (95\% CI) & Adjusted OR (95\% CI) \\
\hline \multicolumn{5}{|l|}{ Age } \\
\hline $18-34$ years & & $84(59.2)$ & (reference) & (reference) \\
\hline $35-44$ years & & $162(64.3)$ & $1.2(0.8-1.9)$ & $1.1(0.7-1.7)$ \\
\hline $45-54$ years & & $346(70.2)$ & $1.6(1.1-2.4)$ & $1.5(1.0-2.3)$ \\
\hline 55-64 years & & $352(71.0)$ & $1.7(1.1-2.5)$ & $1.5(1.0-2.4)$ \\
\hline 65 years or older & & $266(79.2)$ & $2.6(1.7-4.0)$ & $2.4(1.5-3.9)$ \\
\hline \multicolumn{5}{|l|}{ Race/ethnicity } \\
\hline White, non-Hispanic & & $652(67.9)$ & (reference) & (reference) \\
\hline Black, non-Hispanic & & $393(77.7)$ & $1.6(1.3-2.1)$ & $1.5(1.2-2.0)$ \\
\hline Hispanic & & $71(64.5)$ & $0.9(0.6-1.3)$ & $1.1(0.7-1.7)$ \\
\hline Other, specified & & $40(65.6)$ & $0.9(0.5-1.6)$ & $1.2(0.7-2.1)$ \\
\hline Unknown & & $54(65.9)$ & $0.9(0.6-1.5)$ & $0.8(0.5-1.4)$ \\
\hline \multirow[t]{2}{*}{ Gender } & Male & $838(68.5)$ & (reference) & (reference) \\
\hline & Female & $372(75.2)$ & $1.4(1.1-1.8)$ & $1.5(1.1-2.0)$ \\
\hline \multirow[t]{2}{*}{ Copayment Required } & No & $697(74.0)$ & (reference) & (reference) \\
\hline & Yes & $513(66.0)$ & $0.7(0.6-0.8)$ & $0.7(0.6-0.9)$ \\
\hline \multicolumn{5}{|l|}{ Body Mass Index } \\
\hline $27-29 \mathrm{~kg} / \mathrm{m}^{2}$ (overweight) & & $33(45.8)$ & (reference) & (reference) \\
\hline $30-34 \mathrm{~kg} / \mathrm{m}^{2}$ (obesity class I) & & $276(71.9)$ & $3.0(1.8-5.1)$ & $2.1(1.2-3.7)$ \\
\hline $35-39$ kg/m² (obesity class II) & & $382(72.5)$ & $3.1(1.9-5.1)$ & $2.1(1.2-3.7)$ \\
\hline $40+\mathrm{kg} / \mathrm{m}^{2}$ (obesity class III) & & $519(70.5)$ & $2.8(1.7-4.6)$ & $1.8(1.1-3.2)$ \\
\hline \multicolumn{5}{|l|}{ Obesity-Related Comorbidities } \\
\hline \multirow[t]{2}{*}{ Cardiovascular Disease } & No & $1,155(69.7)$ & (reference) & (reference) \\
\hline & Yes & $55(88.7)$ & $3.4(1.5-7.5)$ & $2.8(1.2-6.4)$ \\
\hline \multirow[t]{2}{*}{ Diabetes } & No & $772(68.1)$ & (reference) & (reference) \\
\hline & Yes & $438(74.9)$ & $1.4(1.1-1.7)$ & $1.2(0.9-1.5)$ \\
\hline \multirow[t]{2}{*}{ Hyperlipidemia } & No & $534(68.0)$ & (reference) & \\
\hline & Yes & $676(72.4)$ & $1.2(1.0-1.5)$ & -- \\
\hline \multirow[t]{2}{*}{ Hypertension } & No & $452(66.5)$ & (reference) & \\
\hline & Yes & $758(73.0)$ & $1.4(1.1-1.7)$ & -- \\
\hline \multirow[t]{2}{*}{ Non-Alcoholic Fatty Liver Disease } & No & $1,180(70.3)$ & (reference) & \\
\hline & Yes & $30(73.2)$ & $1.2(0.6-2.3)$ & -- \\
\hline \multirow[t]{2}{*}{ Obstructive Sleep Apnea } & No & $713(69.8)$ & (reference) & \\
\hline & Yes & $497(71.2)$ & $1.1(0.9-1.3)$ & -- \\
\hline
\end{tabular}




\begin{tabular}{|c|c|c|c|c|}
\hline & & $\begin{array}{c}\text { Received Orlistat, } \mathrm{N} \text { (\% of } \\
\text { WMM) }\end{array}$ & Crude OR (95\% CI) & Adjusted OR (95\% CI) \\
\hline Osteoarthritis & No & $833(69.1)$ & (reference) & \\
\hline & Yes & $377(73.5)$ & $1.2(1.0-1.6)$ & -- \\
\hline Depression & No & $683(71.4)$ & (reference) & \\
\hline & Yes & $527(69.1)$ & $0.9(0.7-1.1)$ & -- \\
\hline Gastroesophageal Reflux Disorder & No & $905(70.3)$ & (reference) & \\
\hline & Yes & $305(70.8)$ & $1.0(0.8-1.3)$ & -- \\
\hline Low Back Pain & No & $641(67.5)$ & (reference) & (reference) \\
\hline & Yes & $569(74.0)$ & $1.4(1.1-1.7)$ & $1.4(1.1-1.8)$ \\
\hline Other Physical Comorbidities & & & & \\
\hline Congestive Heart Failure & No & $1,136(69.8)$ & (reference) & reference \\
\hline & Yes & $74(81.3)$ & $1.9(1.1-3.2)$ & $1.9(1.1-3.4)$ \\
\hline Chronic Obstructive Pulmonary Disorder & No & $979(69.8)$ & (reference) & \\
\hline & Yes & $231(73.1)$ & $1.2(0.9-1.5)$ & -- \\
\hline Renal Disease & No & $1,152(70.2)$ & (reference) & \\
\hline & Yes & $58(75.3)$ & $1.3(0.8-2.2)$ & -- \\
\hline Other Mental Health Comorbidities & & & & \\
\hline Alcohol Abuse & No & $1,192(71.3)$ & (reference) & (reference) \\
\hline & Yes & $18(37.5)$ & $0.2(0.1-0.4)$ & $0.4(0.2-0.9)$ \\
\hline Substance Abuse & No & $1,125(73.5)$ & (reference) & (reference) \\
\hline & Yes & $85(45.0)$ & $0.3(0.2-0.4)$ & $0.4(0.3-0.5)$ \\
\hline Psychosis & No & $1,167(70.7)$ & (reference) & \\
\hline & Yes & $43(63.2)$ & $0.7(0.4-1.2)$ & -- \\
\hline
\end{tabular}

